\title{
Safety Evaluation of Urban Shield Hyperbolic Tunneling Construction Underneath Buildings
}

\author{
ZHU Lei ${ }^{1, *}$, PENG Jianhe ${ }^{2}$ and REN Quhong ${ }^{3}$ \\ ${ }^{1}$ Department of Civil Engineering, Hefei University, Hefei Anhui, 230601, China \\ ${ }^{2}$ Anhui and Huaihe River Water Resources Research Institute, Hefei Anhui, 230099, China \\ ${ }^{3}$ Engineering Science Center of REENER Company, C.U. 15100, Aalto, Finland
}

Received 21 July 2015; Accepted 2 November 2016

\begin{abstract}
In urban bustling areas, underground construction will inevitably pass through the existing buildings, either on the face or on the sides, which will cause various deformations to the building foundation and damages, such as cracking and breakage to the walls. Evaluating the deformation during building construction and use by field structure detection, measurement, and numerical calculation, particularly on whether the foundation deformation and the lateral displacement are within the residual displacement capability, is necessary to ensure the normal use of the neighboring building during shield excavation. Based on a real urban tunneling project in Hefei expansive soil, this study conducted field detection and measurement and fixed the residual displacement capability of the building foundation. With regard to the geological and hydrogeological condition of the running tunnel, design material, and engineering methodology, this study adopted the finite differential element software FLAC3D5.0. This software was used to calculate and analyze the law of the deformation of the building foundation and the lateral displacement of an under-passed building during shield hyperbolic tunneling construction. Results show that during the periods when the building is in use and during shield excavation, the maximum value of the lateral displacement of the building is $32.6 \mathrm{~mm}$ and the minimum value is $15.7 \mathrm{~mm}$, which are within the limit value $\mathrm{H} / 450$. The maximum settlement difference of the adjacent foundation is $0.71 \% \mathrm{~L}$ and the minimum is $0.29 \% \mathrm{~L}$, which are within the limit value of $2 \% \mathrm{~L}$. Results indicate that the deformation and the lateral displacement of the building foundation during shield hyperbolic tunneling construction are all within the residual displacement value. This study reduces the risk of tilting, settling, and collapsing for under-passed and neighboring buildings; it offers informative technical support for the success of passing under buildings during shield hyperbolic tunneling construction.
\end{abstract}

Keywords: Shield tunneling, Hyperbolic tunneling, Under-passed building, Residual deformation, Safety evaluation

\section{Introduction}

Urban tunneling construction, which is different from other types of mountain tunneling construction, is challenged by high risks, complicated techniques, unpredictable threats, and great social influences. In urban bustling areas, underground construction will inevitably pass through the existing buildings either on the face or on the sides, which will cause various deformations to the buildings, such as foundation settlement, differential settlement, tilting, and damages, including cracking or breakage to the walls. The damages to the buildings can be severe and prevent normal use, or worse, lead to the collapse of buildings. For instance, damages of different degrees were brought to buildings in London, such as the Elizabeth House, Leeds Hotel, and Mansion House, which were passed through by the extended subway JLE, whose construction started in the mid-1990s [1]. The reason of the failure was that, in the study of residual displacement capability, the existing buildings were considered as new and the deformation of the buildings during construction and use was not assessed. Thus, the residual displacement capability was exaggerated, which

*E-mail address: zhuleianhui@163.com

ISSN: $1791-2377 @ 2016$ Eastern Macedonia and Thrace Institute of Technoloay. All rights reserved. buried hidden threats to the underground shield construction. Therefore, the status quo and deformation standard of buildings are of crucial importance in the study of safety evaluation in urban shield hyperbolic tunneling construction.

This study focuses on a real tunneling construction project in Hefei, China, and adopts the finite difference software FLAC3D5.0 to construct a 3D elastoplastic constitutive model. This model is used to calculate the dynamic foundation deformation of the under-passed building, and the safety of the under-passed building is evaluated vis-à-vis the status quo in urban shield hyperbolic tunneling construction.

\section{State of the art}

With the help of rapidly developed computer-assisted calculation, both domestic and foreign scholars have shed light on the effect of underground tunneling construction on under-passed or side-passed buildings. Wei Gang et al. (2009) [2] and Akhaveissy (2011) [3] adopted a 2D finite element method to explore the effect of underground shield tunneling on the existing buildings. Liu Bo et al. (2006) [4], Wang Zhongxu et al. (2014) [5], and Wei Gang et al. (2014) [6]predicted the law of foundation displacement caused by 
tunneling excavation through 3D finite calculation. Jiang Yiliang (2011) [7] performed a field test in some sections of the extensive line of the Guangzhou Subway Nos. 2 and 8 to study the two-phase horizontal displacement. He Chuan et al. (2012) [8] conducted an indoor simulation and determined the law of the effect of balanced shield excavation on soil deformation. Fan Zuowen et al. (2013) [9] utilized a soil pressure balance shield excavation model and studied the stability of the excavated section and foundation settlement in a sandy gravel construction in Beijing. Finno et al. (2005) [10], Son (2007) [11], Dan (2010) [12], Bryson (2010) [13], and Namazi (2012) [14] explored the deformation of a 3D frame structure on the ground caused by a foundation pit excavation and evaluated the extent of the damage on the building. Zhu Fengbin (2013) [15], Li Tao (2013) [16], Zhang Mingju (2013) [17], and Ren Jianxi (2014) [18] predicted the law of foundation displacement caused by the tunneling excavation with a $3 \mathrm{D}$ finite element calculation and studied the responses of the neighboring buildings to the deformation. All the above studies were achieved through either indoor simulation or numerical calculation, which partly simplified the problem and utilized the residual displacement capability of buildings without considering the displacement of the buildings during construction and use.

Therefore, based on a real tunneling project in Hefei expansive soil, this study adopts the finite difference software FLAC3D5.0 and evaluates the status quo of the under-passed building to evaluate the effect of urban shield hyperbolic tunneling construction on the safety of the underpassed building. The methodology applied in this study is easy to operate, which can shed light to the safety evaluation of similar projects. The study result offers scientific and valid technical support for urban shield hyperbolic tunneling construction underneath existing buildings, which can

effectively reduce such risks as titling, over-degree settlement, and even collapse during tunneling construction.

The rest of this paper is organized as follows. Part 3 describes the approach and methodology of the safety evaluation of the building and constructs a $3 \mathrm{D}$ calculation model based on the basic condition of the building and the geographic position of the subway track. Part 4 evaluates the safety condition of the building under current circumstances, analyzes the dynamic foundation displacement of the underpassed building during shield tunneling, and explores the effect of construction on the under-passed building. The last part concludes the study.

\section{Methodology}

\subsection{Evaluation approach}

The safety evaluation of the under-passed building should be conducted before tunneling construction to ensure its normal use and to meet the requirements of the Interim Measures for the Safety and Quality Management of Urban Rail Transit Projects issued by the China Ministry of Housing and Urban and Rural Development [2010] (Document No. 5). The safety evaluation includes the following: (1) current condition of the building; (2) status of soil foundation; (3) size and structure of the building; (4) outward appearance, distribution of surface cracks, strength, and degree of carbonation of concrete; (5) calculation and analysis on the safety of building structures; (6) lateral displacement, tilting, relative differential settlement of column foundation, and settlement of the main structure; (7) relative residual displacement capability; and (8) evaluation of the effect of tunneling construction on the under-passed building. The technology roadmap of the construction safety evaluation is as follows:

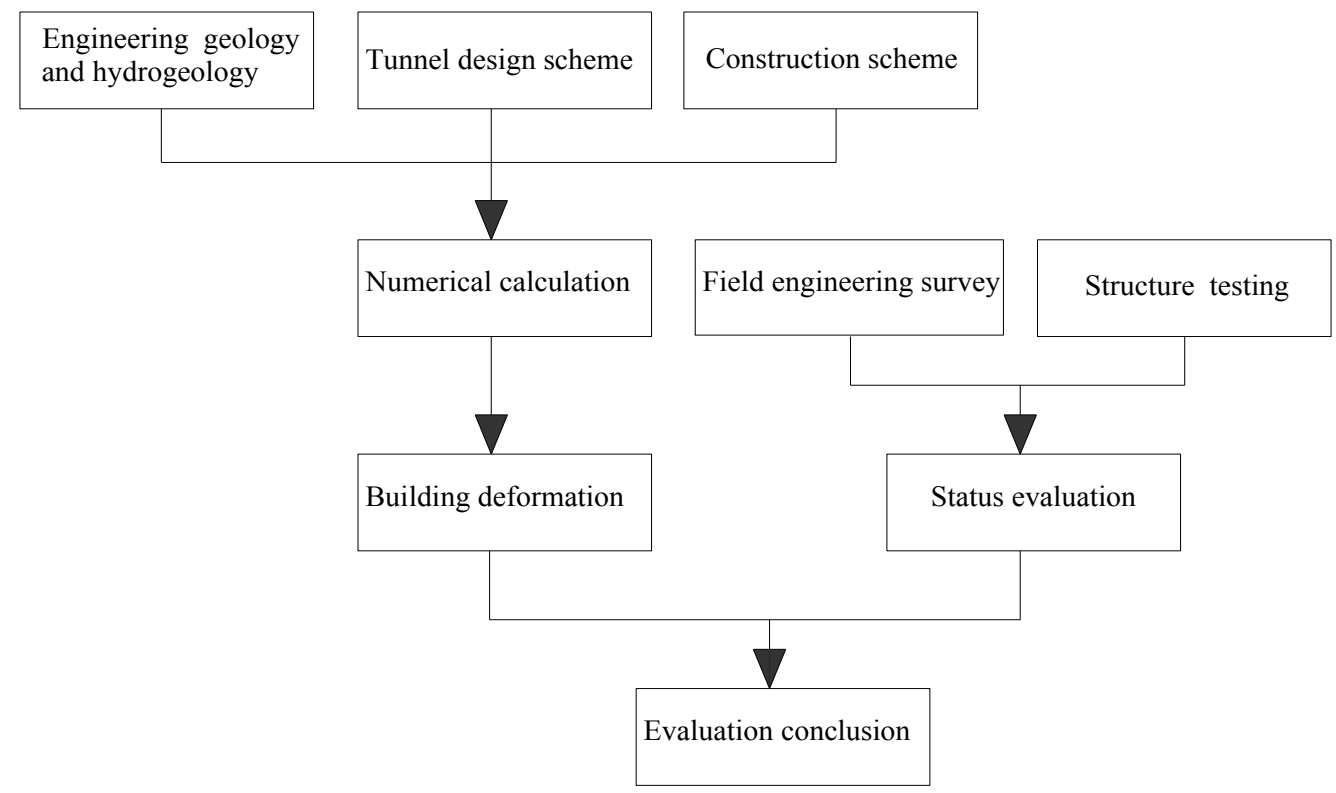

Fig. 1. Technology roadmap of construction safety evaluation

\subsection{Fixing criteria for the foundation displacement value of the existing building}

Building displacement control criteria are a prerequisite for the subway tunnel design and the foundation for building evaluation. In urban subway construction, the foundation settlement value should be within $30 \mathrm{~mm}$, the uplift value is within $10 \mathrm{~mm}$, and the foundation extra tilting is within $1 / 300$. These value limits are fixed because of the experience of experts, which lack scientific support. Owing to the different load-bearing ability and displacement of the building caused by different foundation types, structures, time in use, maintenance, functions, and importance, the residual displacement capability of the building should be evaluated according to the current condition of the building and the control criteria. 
The displacement control criteria are different because the technical codes in different countries vary from one another. Years of experience in safety appraisal and engineering accident identification have proven that the Item 5.3.4 in the Design Code for Building Foundation (GB 50007-2011) is suitable to be the control criterion, considering that the code prescribes the accepted values of foundation displacement. The displacement of the old buildings that has taken place during construction and use should be included as part of the foundation displacement because the code is oriented to newly built buildings.

\subsection{Establishment of a 3D calculation model}

\subsubsection{Brief introduction to the running tunnel and the under-passed building}

Three plane curves exist for the running tunnel, with semidiameters of 650,1000 , and $2000 \mathrm{~m}$. The hyperbolic tunnel axis in the shield section varies from $14 \mathrm{~m}$ to $16.5 \mathrm{~m}$, with a buried depth of $19 \mathrm{~m}$. A soil pressure balance shield machine is used in construction. The technical parameters are as follows. The cutter is $6.4 \mathrm{~m}$ in external diameter. The shield is $6.34 \mathrm{~m}$ in external diameter, $7.00 \mathrm{~mm}$ in thickness, and 7.74 in length. The shield tail is $3.15 \mathrm{~mm}$ in length. The segment is $6.00 \mathrm{~m}$ in external diameter, $5.40 \mathrm{~m}$ in internal diameter, $0.30 \mathrm{~m}$ in thickness, and $1.50 \mathrm{~m}$ in width for each ring. The concrete used is leveled C50 in strength.

The under-passed building is a complex building of policemen reception in the Anhui Reeducation Bureau, which is in the upside of the running tunnel between the Qianshan Road Station and the Qingyang Road Station. The detailed geographic location is illustrated in Fig. 2.

The building is a seven-floor frame structure with a bearing stratum foundation that has a capacity of $260 \mathrm{kPa}$. The foundation is independent, with a concrete strength leveled $\mathrm{C} 20$. The beam columns are all cast-in-place concrete, with strength leveled C30 in floors 1-3, C25 in floors 3-7, and C25 in components, such as stairs.

\subsubsection{Calculation model}

The finite difference software FLAC3D5.0 is adopted for numerical simulation to analyze the dynamic deformation of the independent foundation of the building during shield excavation. FLAC3D5.0 software solves the 3D problems in shield tunneling excavation and the problems in the interaction between the segment-supporting structure and soil body, as well as simulates the mechanical behavior, such as yielding, plastic flowing, softening, or deformation under the load effect of the soil body. The parameter for the plane calculation model is set as $\mathrm{X} \times \mathrm{Y}=48140 \mathrm{~mm} \times 26525$ $\mathrm{mm}$ to meet the accuracy requirement. The relationship between the running tunnel of the subway to be constructed and the under-passed building is shown in Figs. 4 and 5, and the cross-section drawing is shown in Fig. 6. The building foundation is simulated by changing the parameter of the equivalent circle zone. The upper load is matched with the evenly distributed load on top of the building foundation.

Boundary conditions are set in the model. The bottom boundaries are confined in directions X, Y, and Z. Four side boundaries are confined in directions $\mathrm{X}$ or $\mathrm{Y}$, whereas the upper face has no confinement.

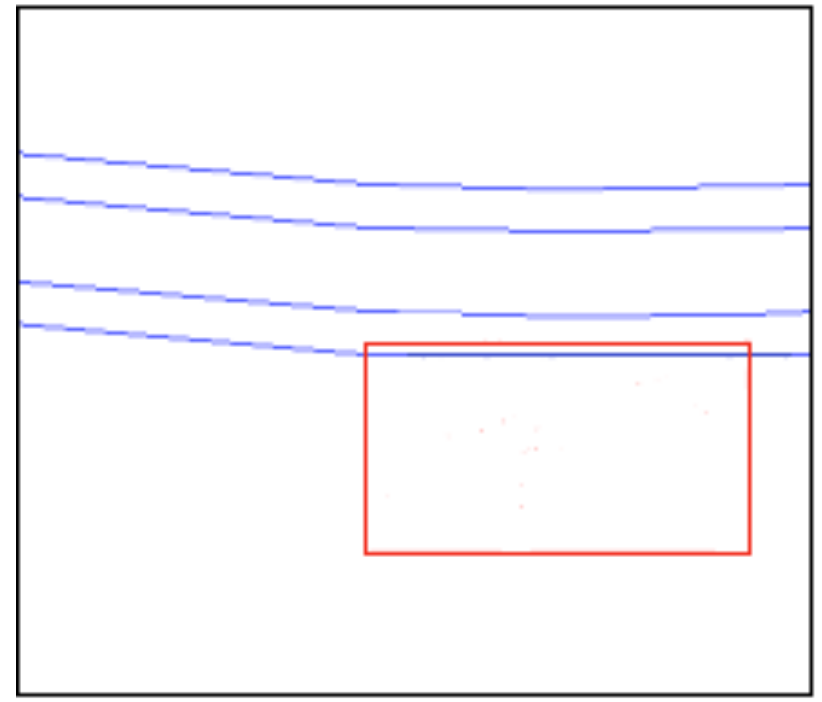

Fig.2. Drawing of the position relationship between the running tunnel and the building

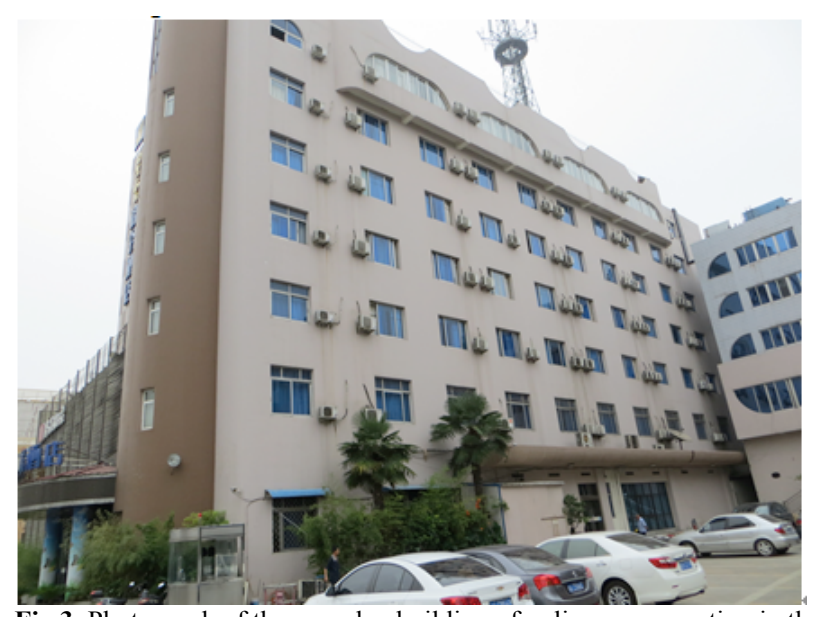

Fig.3. Photograph of the complex building of policeman reception in the Anhui Reeducation Bureau

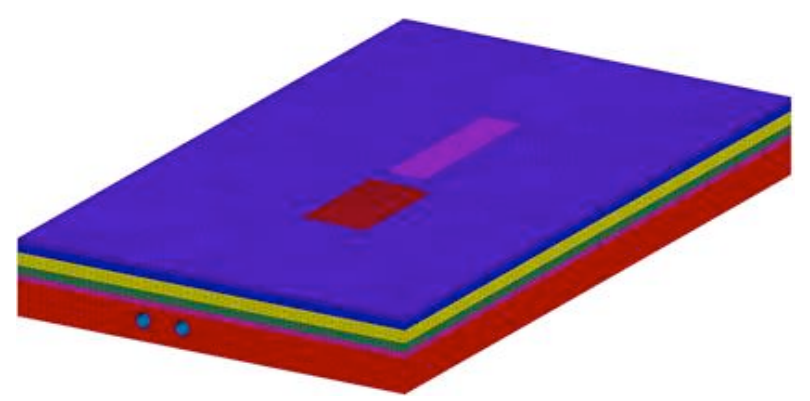

Fig.4. Position relationship between the running tunnel and the existing building

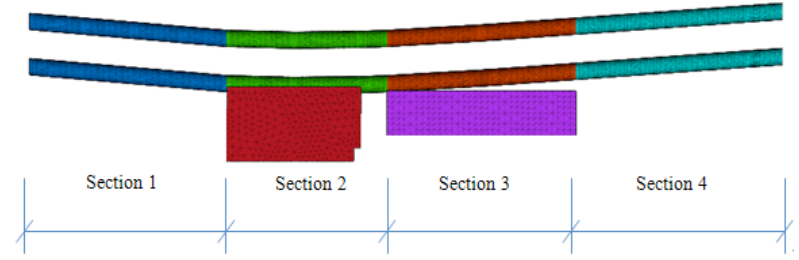

Fig.5. Plane graph of the running tunnel and the existing building 




Fig.6. Cross-section drawing of the running tunnel and the existing building

\subsubsection{Constitutive model and calculation parameters}

Zero models are used to simulate the soil excavation, and Mohr-Coulomb code is adopted to match the yielding of soil. According to the geotechnical investigation report, the thickness of various soil bodies in shallow layers and their physical and mechanical parameters are listed in Table 1. The segment is an elastic element, and the related parameters are shown in Table 2. The weight of the foundation is $25 \mathrm{kN} / \mathrm{m}^{3}$, the bulk modulus is $6 \times \mathrm{e}^{3} \mathrm{MPa}$, and the sheer modulus is $4 \times \mathrm{e}^{3} \mathrm{MPa}$. Although the underground water in the shield running tunnel to be constructed is deep, a dewatering treatment is not needed during the shield tunneling excavation. Therefore, the effect of underground water on the deformation of the foundation should be disregarded.

Table1. Formation parameter

\begin{tabular}{|c|c|c|c|c|c|c|}
\hline Name of soil & $\begin{array}{c}\text { Thickness } \\
\text { m }\end{array}$ & $\begin{array}{l}\text { Weight } \\
\mathrm{kN} / \mathrm{m}^{3}\end{array}$ & $\begin{array}{c}\text { Cohesion } \\
\text { kPa }\end{array}$ & $\underset{\circ}{\text { Angle }}$ & $\begin{array}{c}\text { Modulus } \\
\text { MPa }\end{array}$ & Poisson ratio \\
\hline Artificial fill & 4.6 & 18.52 & 16 & 12.2 & 2.22 & 0.39 \\
\hline Clay (1) & 2.1 & 19.73 & 25 & 9.3 & 6.51 & 0.35 \\
\hline Clay (2) & 3.3 & 19.95 & 45 & 11.2 & 10.12 & 0.31 \\
\hline Completely weathered sandstone & 3.2 & 20.12 & 32 & 12.1 & 32.11 & 0.30 \\
\hline Intermediary weathered sandstone & 2.1 & 21.32 & 140 & 30.2 & 18021 & 0.22 \\
\hline Intermediary weathered sandstone & 15.4 & 22.91 & 140 & 30.1 & 108.32 & 0.22 \\
\hline
\end{tabular}

Table 2. Tunnel segment calculation parameters

\begin{tabular}{c|c|c|c|c}
\hline $\begin{array}{c}\text { Supporting } \\
\text { type }\end{array}$ & $\begin{array}{c}\text { Thickness } \\
\mathbf{m m}\end{array}$ & $\begin{array}{c}\text { Density } \\
\mathbf{K g} / \mathbf{m}^{\mathbf{3}}\end{array}$ & $\begin{array}{c}\text { Elastic modulus } \\
\mathbf{G P a}\end{array}$ & $\begin{array}{c}\text { Poisson } \\
\text { ratio }\end{array}$ \\
\hline Lining segment & 300 & 2500.0 & 34.5 & 0.2 \\
\hline
\end{tabular}

\section{Result analysis and discussion}

\subsection{Investigation and evaluation of the current conditions} of the building

\subsubsection{Inspection of structural damage}

In the inspection of the external appearance, significant cracks or other abnormal deformation are not found in the beam, planet, or column of the building.

\subsubsection{Detection of the working state of the foundation} A ground penetrating radar is used to detect nondestructively the internal structure of the building foundation. Detected statistics show the normal working state of the foundation.

\subsubsection{Lateral displacement of the building}

According to the structural type and deformation control criterion, the combined displacement of both horizontal and vertical lateral displacement is reckoned to analyze the

Table 3. Lateral displacement of the building tilting condition and to evaluate the safety of the building and the residual deformation capability of the lateral displacement. The detailed distribution of the corner column-monitoring points is shown in Fig. 7.

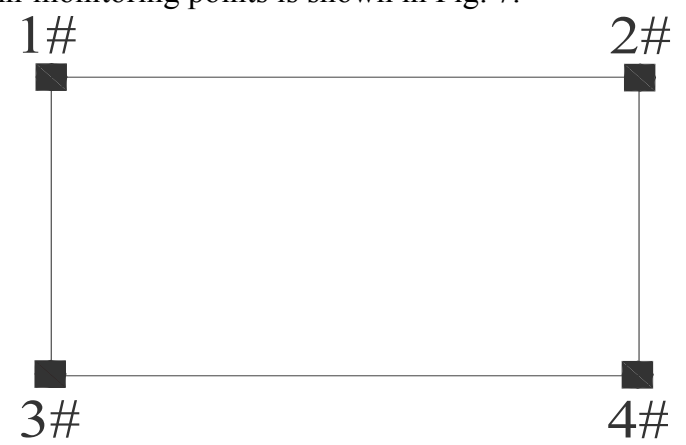

Fig.7. Layout drawing of monitoring points for lateral displacement

Total-Station instrument Leica TCR1202 is used to measure the lateral displacement of the four top points of the building, and the result is provided in Table 3 .

\begin{tabular}{c|c|c|c|c}
\hline \multirow{2}{*}{ Monitoring point } & Lateral displacement (mm) & Lateral displacement & Height \\
\cline { 2 - 5 } & Horizontal & Vertical & $\mathbf{( m m})$ & 23100 \\
\hline $1 \#$ & 12 & 16 & 20 & 23100 \\
$2 \#$ & 14 & 24 & 14.8 & 23100 \\
$3 \#$ & -8 & -12 & 17.9 & 23100 \\
4\# & -8 & -16 & & \\
\hline
\end{tabular}

Note: The limiting value is specified in the reliability assessment standard of civilian building; $\mathrm{H}$ is the height for structure tops.

Table 3 indicates that the lateral displacement of the corner columns of the main structure varies from $14.4 \mathrm{~mm}$ to $27.8 \mathrm{~mm}$, which is below $51.3 \mathrm{~mm}(\mathrm{H} / 450)$ and within the limit value prescribed by the Standard for appraisal of the safety of civilian buildings. The result is consistent with the fact that no abnormal problem is found in the external appearance of the building.

4.1.4 Relative foundation settlement and settlement difference

The monitoring points are settled on the adjacent independent foundations, and the detailed positions are 
shown in Fig. 8. Instruments are used to measure each independent foundation and the relative settlement and settlement difference of both horizontal and vertical adjacent foundations can then be calculated before shield excavation. The detailed statistics are illustrated in Figs. 4 and 5.

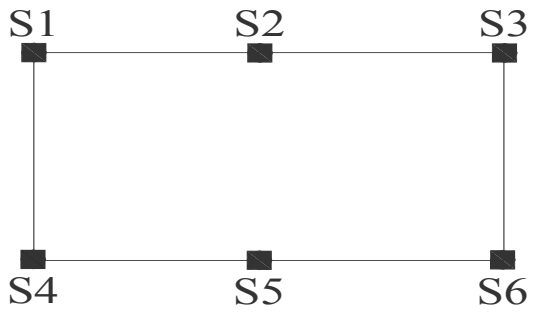

Fig. 8. Layout drawing of monitoring points for foundation settlement

Table 4. Settlement difference in longitudinal adjacent foundation before shield excavation

\begin{tabular}{c|c|c|c}
\hline \multirow{2}{*}{ Monitoring points } & Relative settlement & Space between foundations & Settlement difference in adiacent foundations \\
\cline { 2 - 4 } & $(\mathbf{m m})$ & $\mathbf{( m )}$ & $0.60 \% \mathrm{~L}$ \\
S1 & 5 & 21.60 & $0.34 \% \mathrm{~L}$ \\
S2 & 18 & 23.40 & $0.69 \% \mathrm{~L}$ \\
S3 & 10 & 21.60 & $0.38 \% \mathrm{~L}$ \\
S4 & 0 & 23.40 & \\
S5 & 15 & & \\
S6 & 6 &
\end{tabular}

Note: $\mathrm{L}$ refers to the space between adjacent foundations.

§Table 4 shows that the maximum value of the relative foundation settlement for the complex building of policemen reception in the Anhui Reeducation Bureau is $18 \mathrm{~mm}$. The spaces between vertical adjacent foundations are $21.6 \mathrm{~m}$ and $23.4 \mathrm{~m}$. The maximum value of the vertical settlement difference is $0.69 \% \mathrm{~L}$, and the minimum value is $0.34 \% \mathrm{~L}$.

Table 5. Settlement difference in adjacent foundations before shield construction

\begin{tabular}{|c|c|c|c|}
\hline \multirow{2}{*}{ Monitoring points } & Relative settlement & Space between foundations & Settlement difference of adjacent foundations \\
\hline & $(\mathbf{m m})$ & (m) & \\
\hline $\begin{array}{l}\mathrm{S} 1 \\
\mathrm{~S} 4\end{array}$ & $\begin{array}{l}5 \\
0\end{array}$ & 26.00 & $0.19 \% \circ \mathrm{L}$ \\
\hline $\begin{array}{l}\text { S2 } \\
\text { S5 }\end{array}$ & $\begin{array}{l}18 \\
15\end{array}$ & 26.00 & $0.12 \% \circ \mathrm{L}$ \\
\hline $\begin{array}{l}\text { S3 } \\
\text { S6 }\end{array}$ & $\begin{array}{c}10 \\
6 \\
\end{array}$ & 26.00 & $0.15 \% \circ \mathrm{L}$ \\
\hline
\end{tabular}

Note: $\mathrm{L}$ refers to the space between adjacent foundations.

Table 5 implies that the maximum value of relative foundation settlement is also $18 \mathrm{~mm}$. The spaces between horizontal adjacent foundations are equally $26.00 \mathrm{~m}$. The maximum value of horizontal settlement difference is $0.19 \% \mathrm{~L}$, and the minimum value is $0.12 \% \mathrm{~L}$.

From Tables 4 and 5, the maximum value of the settlement difference in adjacent foundations before shield excavation is and the minimum value is, which are within the limit values prescribed in the Code for the design of the building foundation [19]. Results are in accordance with the fact that the building is in normal operations.

4.1.5 Prediction of the residual deformation capability of the under-passed building

Any building that satisfies the requirement for function has a capability to counter the ground displacement and deformation. This characteristic is termed the allowed deformation capability. The crucial tasks for the safety evaluation of the under-passed building are to evaluate the residual deformation capability and to fix the deformation control value after considering the allowed deformation value and the already deformed value.

\subsubsection{Prediction of the residual deformation capability} for lateral displacement

(1) Fixing the limit value for the lateral displacement of the under-passed building

The limit value for lateral displacement is prescribed in the Standard for appraisal of the safety of civilian buildings, as shown in Table 6 . The limit value speculated in the code is oriented to new buildings, and the residual deformation capability of the lateral displacement is related to the structure type and the displacement that has already occurred when in use.

Table 6. Limit value of the lateral displacement of the building

\begin{tabular}{|c|c|c|c|}
\hline \multicolumn{3}{|c|}{ Structure type } & $\begin{array}{c}\text { Lateral displacement } \\
\text { on tops }\end{array}$ \\
\hline \multirow{4}{*}{$\begin{array}{l}\text { Concrete structure } \\
\text { or steel structure }\end{array}$} & \multicolumn{2}{|c|}{$\begin{array}{c}\text { Single-story } \\
\text { building }\end{array}$} & $<\mathrm{H} / 400$ \\
\hline & \multicolumn{2}{|c|}{ Multi-story building } & $<\mathrm{H} / 450$ \\
\hline & \multirow{2}{*}{ High-rise building } & Frame & $<\mathrm{H} / 550$ \\
\hline & & frame-shear wall & $<\mathrm{H} / 700$ \\
\hline
\end{tabular}

(2) Residual deformation capability for the lateral displacement of the under-passed building
The measurement and calculation results of the lateral displacement of the building before shield excavation indicate that the maximum value of the lateral displacement 
for corner columns in the main structure is $27.8 \mathrm{~mm}$ and the minimum value is $14.4 \mathrm{~mm}$, which are within the limit value prescribed by the Standard for appraisal of the safety of civilian buildings of $51.3 \mathrm{~mm}(\mathrm{H} / 450)$. Therefore, the maximum value of residual lateral displacement for the corner columns is $36.9 \mathrm{~mm}$, and the minimum value is 23.5 $\mathrm{mm}$.

\subsubsection{Prediction of the residual deformation capability of the under-passed building foundation}

The detection result of the relative settlement and settlement difference of both the horizontal and vertical adjacent foundations before shield excavation indicates that the maximum settlement difference in the adjacent foundation is $0.69 \% \mathrm{~L}$ and the minimum is $0.12 \% \mathrm{~L}$. The maximum value of the residual settlement difference is $1.88 \% \mathrm{~L}$ and the minimum value is $1.31 \% \mathrm{~L}$, considering that the limit value of settlement difference for industrial and civilian buildings prescribed in the code is $2 \% \mathrm{~L}$.

\subsubsection{Safety evaluation of the current situation of the under-passed building}

The lateral displacements on top of the main structure of the building are all within the limit value prescribed in the Standard for appraisal of the safety of civilian buildings. The top of the buildings all have a certain residual deformation capability.

The settlement differences in adjacent foundations are within the limit value set by the Design Code for Building Foundation, which means a certain residual deformation capability exists between adjacent foundations.

The building foundation does not exhibit defects and works well. No abnormal deformation or cracks are observed in the supporting components caused by such factors as foundation settlement or load. The carrying capacity of the ground, foundation, and main structure components can meet the prescription.

With reference to the Standard for appraisal of the safety of civilian buildings and the Design Code for Building Foundation, this project can meet the safety requirements for normal use.

\subsection{Safety evaluation of the building after tunneling excavation}

According to the shield tunneling engineering process, the hyperbolic tunneling excavation is simulated with the following steps: (1) setting the 3D model; (2) calculating the initial stress field; (3) resetting displacement; (4) calculating the initial stress field under the load effect; (5) resetting displacement; (6) calculating excavation in different steps; and (7) analyzing the calculation results. In the simulation, the deformation of the ground and the building can be seen in Fig.9. As the building has been in use for years, it can be safely inferred that the ground settlement has been stable in light of the physic and mechanics properties of ground soil and the deformation of the ground and the building during shield tunneling is caused by the disturbance of soil. Fig.9 shows the deformation of the ground and the foundation mainly takes place in certain scope of double tunnels and their sides.

\subsubsection{Analysis of the lateral displacement of the building} The lateral displacement of the four corner columns gradually changes with the advancing of shield excavation. The total displacement for all sections is illustrated in Fig. 10. The running tunnel is divided into four sections from west to east. Section 1 starts from the initial point to the boundary of the building. Section 2 is the area directly below the under-passed building. Sections 3 and 4 are the areas that already passed the building. The details are shown in Fig. 7.

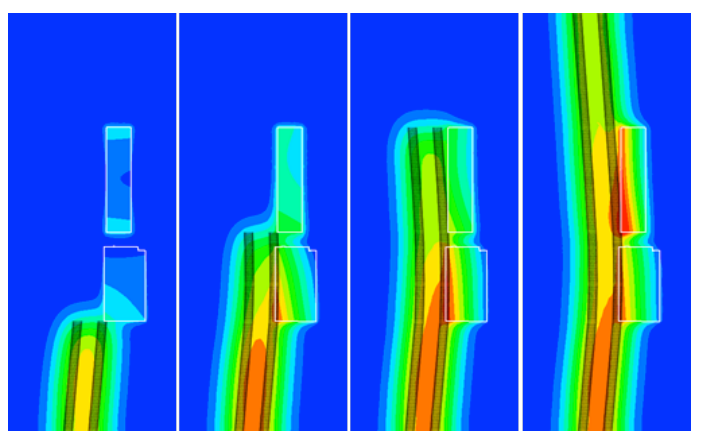

Fig.9. Cloud chart of buildings and ground deformation after shield construction

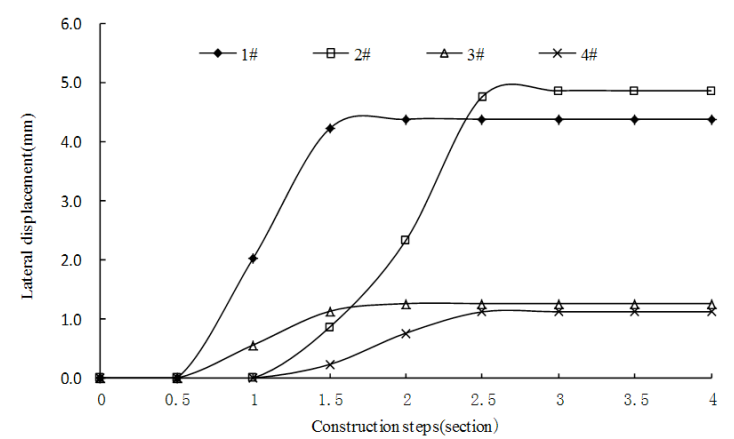

Fig.10. Chart of the settlement in monitoring points

Fig.10 implies that in Section 1, when the excavation approaches the building, the lateral displacement of monitoring points $1 \#$ and $3 \#$ gradually rises, with an obvious change in point $3 \#$ and a minor change in point $1 \#$. The lateral displacement in points $2 \#$ and $4 \#$ does not change. In Section 2, the lateral displacement in monitoring points $1 \#$, $2 \#$, and $4 \#$ gradually rises horizontally, whereas the lateral displacement of monitoring point $3 \#$ gradually declines vertically. With further excavation, the lateral displacement in points $2 \#$ and $4 \#$ continues rising, and the change in point $2 \#$ is more obvious than that in point $4 \#$. The horizontal lateral displacement of point $4 \#$ changes insignificantly. When the excavation is $30 \mathrm{~m}$ away from the building, the lateral displacement of all monitoring points becomes stable. The maximum lateral displacement is $4.76 \mathrm{~mm}$ in point 2\#, which is near the tunnel; the minimum lateral displacement is $1.12 \mathrm{~mm}$ in point $4 \#$, which is rather far from the tunnel.

\subsubsection{Analysis of foundation settlement}

Four corners of the building foundation and two points nearest to the middle of the two long sides are taken as the points for settlement analysis, as shown in Fig. 5, to analyze the effect of a running tunnel construction on the complex building of policemen reception in the Anhui Reeducation Bureau. The settlement value changes with the advancement of shield tunneling, and the total settlement monitored in different points is shown in Fig. 11.

Fig.11 illustrates that in Section 1, when the excavation approaches the building, the settlement begins to appear in the excavation monitoring point near the excavated section. When the excavation arrives at the building, settlement takes 
place in all monitoring points, with obvious changes in $\mathrm{S} 1$, $\mathrm{S} 2$, and S4 and minor changes in S3, S5, and S6. In Section 2 , because the monitoring points $\mathrm{S} 1, \mathrm{~S} 2$, and $\mathrm{S} 3$ lie right above the passing tunnel, the settlement changes greatly in these points, whereas the settlement in S4, S5, and S6 is less. The deformation of the under-passed building during shield excavation takes place vertically and toward the inside tunnel. When the excavation is $30 \mathrm{~m}$ away from the building, the foundation settlement becomes stable. The maximum vertical displacement is $7.23 \mathrm{~mm}$ in $\mathrm{S} 2$, which is near to the tunnel. The minimum vertical displacement is $2.45 \mathrm{~mm}$ in $\mathrm{S} 4$, which is far from the tunnel. The findings indicate that in the process of the excavating face approaching, passing through, and leaving the building, deformation takes place in the nearest foundation both horizontally and vertically, with horizontal deformation as the main deformation. With the rising of horizontal deformation, vertical deformation first rises, then declines in parts of the foundation, and finally ends in tilting toward the tunnel axis. The foundation mainly tilts horizontally because the building is parallel to the tunnel axis vertically.

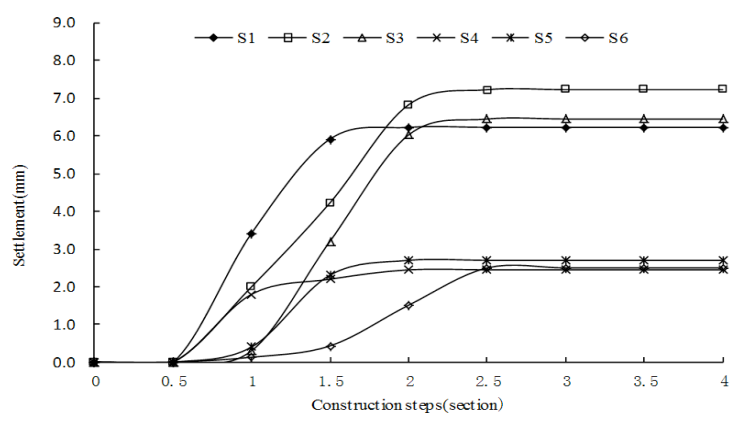

Fig.11. Chart of the settlement in monitoring points

\subsubsection{Safety evaluation}

The effect of shield hyperbolic tunneling on the safety of the under-passed building is evaluated based on the design scheme of the design units and the construction technology of the construction units.

(1) Lateral displacement of the building

The lateral displacement during underground shield tunneling is provided in Table 7.

Tab.7. Lateral displacement of the building

\begin{tabular}{|c|c|c|c|c|c|}
\hline \multirow[t]{2}{*}{ Monitoring point } & \multicolumn{2}{|c|}{$\begin{array}{r}\text { Lateral displacement } \\
(\mathrm{mm})\end{array}$} & \multirow{2}{*}{$\begin{array}{c}\text { Lateral displacement } \\
(\mathrm{mm})\end{array}$} & \multirow{2}{*}{$\begin{array}{c}\text { Height } \\
(\mathbf{m m}) \\
\end{array}$} & \multirow{2}{*}{$\begin{array}{c}\text { Limit value } \\
(\mathrm{mm}) \\
\end{array}$} \\
\hline & Horizontal & Vertical & & & \\
\hline $1 \#$ & 18.1 & 16.4 & 24.4 & 23100 & \\
\hline $2 \#$ & 21.5 & 24.5 & 32.6 & 23100 & $<51.3$ \\
\hline $3 \#$ & -9.9 & -12.2 & 15.7 & 23100 & $(\mathrm{H} / 450)$ \\
\hline $4 \#$ & -10.1 & -16.1 & 19.0 & 23100 & \\
\hline
\end{tabular}

Note: The limiting value is specified in the reliability assessment standard of civilian building; $H$ is the height for structure tops.

Table 7 shows that the maximum value of the lateral displacement of the corner columns is $32.6 \mathrm{~mm}$ and the minimum value is $15.7 \mathrm{~mm}$, which are all below the limit value prescribed by the Standard for appraisal of the safety of civilian buildings of $51.3 \mathrm{~mm}(\mathrm{H} / 450)$. Results show that the lateral displacement of the building during shield tunneling meets the requirement.
(2) Foundation settlement

The value of the relative settlement and the settlement difference after shield tunneling is the total of all the deformation taking place during the period of use and in the tunneling process. The relative settlement and settlement difference of adjacent foundations are given in Tables 8 and 9 .

Table 8. Settlement difference in adjacent foundations after shield construction

\begin{tabular}{c|c|c|c}
\hline \multirow{2}{*}{ Monitoring points } & Relative settlement & Space between foundations & Settlement difference in adiacent foundations \\
\cline { 2 - 4 } & $(\mathbf{m m})$ & 21.60 & \multirow{2}{*}{$0.65 \% \mathrm{~L}$} \\
\hline S1 & $\begin{array}{c}8.8 \\
22.8\end{array}$ & 23.40 & $0.38 \% \mathrm{~L}$ \\
\cline { 2 - 3 } S2 & 14.0 & 21.60 & \multirow{2}{*}{$0.71 \%{ }_{0} \mathrm{~L}$} \\
S3 & 0 & 23.40 & $0.39 \% \mathrm{~L}$ \\
S4 & 15.3 & & \multirow{2}{*}{0} \\
\hline
\end{tabular}

Note: $\mathrm{L}$ refers to the space between adjacent foundations.

Table 8 implies that the maximum value of the relative settlement after the excavation is $22.8 \mathrm{~mm}$. The maximum value of settlement difference in the vertical adjacent foundations is $0.71 \% \mathrm{~L}$, and the minimum value is $0.38 \% \mathrm{~L}$.

Table 9. Settlement difference in adjacent foundations after shield construction

\begin{tabular}{c|c|c|c}
\hline \multirow{2}{*}{ Monitoring points } & Relative settlement & Space between foundations & Settlement difference in adjacent foundations \\
\cline { 2 - 4 } & $(\mathbf{m m})$ & $(\mathbf{m})$ & \\
\hline S1 & 8.8 & 26.00 & $0.34 \% \mathrm{~L}$ \\
S4 & $\begin{array}{c}22.8 \\
15.3\end{array}$ & 26.00 & \multirow{2}{*}{$0.29 \% \mathrm{~L}$} \\
S2 & 14.0 & 26.00 & $0.30 \% \mathrm{~L}$ \\
S5 & 6.1 & & \multirow{2}{*}{0} \\
S3 & & & \\
S6 & & & \\
\hline
\end{tabular}

Note: $\mathrm{L}$ refers to the space between adjacent foundations.

Table 9 shows that the maximum value of relative settlement after excavation is equally $22.8 \mathrm{~mm}$. The maximum value of settlement difference in horizontal adjacent foundations is $0.34 \% \mathrm{~L}$, and the minimum value is $0.29 \% \mathrm{~L}$. The increase 
in the horizontal settlement difference is caused by the tilting of the building toward the tunnel.

From Tables 8 and 9, and considering both the deformation of the building in use and the deformation during excavation, the maximum value of settlement difference after tunneling is and the minimum value is, which are within the limit value speculated in the code.

The structure inspection and appearance detection of the building, as well as the numerical simulation, indicate that the lateral displacement of the building and the maximum settlement difference in adjacent foundations are all within the allowed value prescribed by the code. Hence, the applied design scheme and construction technology can ensure the normal use of the building during shield tunneling construction.

\section{Conclusions}

This study evaluates the effect of shield hyperbolic tunneling on an under-passed building to ensure the safety and normal use of the neighboring buildings during shield tunneling construction. This study analyzes the law of deformation of the existing building foundation during tunneling construction via structure inspection, appearance detection, and safety evaluation of the current state of the building. The residual deformation capability of the building is proven to meet the requirements of the code. The following conclusions are drawn:

(1) During the period when the building is in use and the period of shield excavation, the maximum of the lateral displacement of the building is $32.6 \mathrm{~mm}$ and the minimum is $15.7 \mathrm{~mm}$, which are within the limit value of $\mathrm{H} / 450$. The maximum settlement difference in the adjacent foundation is $0.71 \% \mathrm{~L}$, and the minimum is $0.29 \% \mathrm{~L}$, which are within the limit value of $2 \%$ L. Results indicate that the applied design scheme and construction technology can ensure the normal use of the building during shield tunneling construction.

(2) Measures such as structure inspection and appearance detection of the under-passed building, as well as the numerical simulation and calculation, can be effective means to predict the safety of under-passed buildings during urban shield hyperbolic tunneling construction.

Predictions on the safety of the building can be a reference for construction units, designers, and owners to decide whether to adjust the tunnel route, to change the buried depth, and to solidify the ground to ensure the safety and normal use of under-passed buildings during shield tunneling construction.

Combining numerical calculation and field detection, this study provides a new outlook for the safety evaluation of under-passed buildings during shield construction. The calculation model proposed in this study is simple and close to field practice, which can be applied to similar projects. With the lack of real data in field construction and in indoor experiments, future studies will combine field monitoring information and indoor experimental data with the current evaluation method to provide a more accurate evaluation of the safety of different types of building during shield construction.

\section{Acknowledgements}

This study was funded by the Key Project of Natural Science Research of Anhui Higher Education (KJ2015A151), the Talent Research Fund Project of Hefei University (15RC02), and the Project of Hefei University Key Disciplines Construction of Civil Engineering (2014xk04).

\section{References}

1. Han Xuan, "The analysis and prediction of tunneling-induced building deformations", Xi'an University of Technology press, Xi'an, 2007.

2. Wei Gang, Qiu Xingu, Wei Xinjiang, et al, "Numerical simulation of underground excavated tunnel construction of adjacent structure", Rock and Soil Mechanics, 30( 2), 2009, pp. 547-552.

3. Akhaveissy A H, "Analysis of tunnel and super structures for excavation", Scientia Iranica, 18(1), 2011, pp. 1-8.

4. Liu Bo, TAO Longguang, Ding Chenggang, et al, "Prediction for Ground Subsidence Induced by Subway Double Tube Tunneling", Journal of China University of Mining\&Technology, 35(3), 2013,pp. 356-361.

5. Wang Zhongchang, Wang Haitao, Zhu Xunguo, et al, "Analysis of stratum deformation rules induced by the construction of doubletube parallel shield tunnels for metro", China Railway Science, 34(3), 2013, pp.53-58.

6. Wei Gang, Pang Siyuan, "Study of three dimensional soil deformation caused by double-line parallel shield tunnel construction", Rock and Soil Mechanics, 35(9), 2014, pp. 25622568 .

7. Jiang Xinliang, Li Lin, Yuan Jie, et al, "Dynamic analysis of strata horizontal displacements induced by shield construction of deep tunnel”, Rock and Soil Mechanics, 32(4), 2011, pp. 1186-1192.

8. He Chuan, Wang Yang, Fang Yong, et al, "Similarity model test of Earth-Pressure-Balanced shield tunneling process", China Civil Engineering Journal, 45(2), 2012, pp. 162-169.

9. Fan Zuowen, Zhang Zixin, "Model test of excavation face stability of EPB shield in sandy cobble ground and adjacent building effect", Chinese Journal of Rock Mechanics and Engineering, 32(12), 2013, pp. 2506-2512.

10. Finno R J, Voss Jr F T, Rossow E, et al, "Evaluating damage potential in buildings affected by excavations", Journal of geotechnical and geoenvironmental engineering, 131(10), 2005, pp. 1199-1210.
11. Son M, Cording E J. , "Evaluation of building stiffness for building response analysis to excavation-induced ground movements", Journal of geotechnical and geoenvironmental engineering, 133(8), 2007, pp. 995-1002.

12. Dan K. A, "Theoretical Study on Ground Movement and Building Damage Predictions for Braced Excavations in Undrained Clay", Jadavpur University Kolkata, 2010.

13. Bryson L S, Kotheimer M J. , "Cracking in walls of a building adjacent to a deep excavation", Journal of Performance of Constructed Facilities, 25(6), 2010, pp. 491-503.

14. Namazi E, Mohamad H. , "Assessment of building damage induced by three-dimensional ground movements", Journal of Geotechnical and Geoenvironmental Engineering, 139(4), 2012, pp. 608-618.

15. Zhu Fengbin, Miao Linchang, "Analysis and by shield prediction of ground deformation caused tunnelling adjacent to existing building", Journal of Southeast University (Natural Science Edition), 43(4), 2013, pp. 856-862.

16. Li Tao, Chen Huixian, Liu Bo, et al, "Research on the influence of twin shield tunnel construction on the adjacent high rise building", Journal of Hunan University of Science \&Technology (Natural Science Edition), 28(4), 2013, pp. 43-48.

17. Zhang Miniju, Liu XiaoJuan, Du Yongxiao, "Building settlements induced by shield tunneling in close proximity", Journal of Beijing University of Technology, 39(2), 2013, pp. 214-219.

18. Ren Jianxi, LI Qingyuan, Zheng Zanzan, et al, "Research on the deformation laws of surface and adjacent building induced by shield tunnel", Journal of railway engineering society, 31(1), 2014, pp. 69-74.

19. GB50007-2002, “Code for Design of Building Foundation”, China Architectural Industry Press, Beijing, 2002. 